\title{
Porcine reproductive and respiratory syndrome virus: Genetic diversity of recent British isolates
}

\author{
Jean-Pierre Frossard ${ }^{\mathrm{a}, *}$, Gareth J. Hughes ${ }^{\mathrm{c}, 1}$, David G. Westcott ${ }^{\mathrm{a}}$, Brindha Naidu ${ }^{\mathrm{a}}$, \\ Susanna Williamson ${ }^{b}$, Nicholas G.A. Woodger ${ }^{\mathrm{b}}$, Falko Steinbach ${ }^{\mathrm{a}}$, Trevor W. Drew ${ }^{\mathrm{a}}$ \\ ${ }^{a}$ Animal Health and Veterinary Laboratories Agency - Weybridge, Woodham Lane, New Haw, Surrey KT15 3NB, United Kingdom \\ ${ }^{\mathrm{b}}$ Animal Health and Veterinary Laboratories Agency - Bury St. Edmunds, Rougham Hill, Bury St. Edmunds, Suffolk IP33 2RX, United Kingdom \\ ${ }^{\mathrm{c}}$ Institute of Evolutionary Biology, University of Edinburgh, Ashworth Laboratories, King's Buildings, Edinburgh EH9 3JT, United Kingdom
}

\section{A R T I C L E I N F O}

\section{Article history:}

Received 10 January 2012

Received in revised form 5 November 2012

Accepted 7 November 2012

\section{Keywords:}

Porcine respiratory and reproductive syndrome virus

Molecular evolution

Genetic variation

Molecular epidemiology

Molecular sequence data

Phylogeny

Viral/genetics RNA

\begin{abstract}
A B S T R A C T
Porcine reproductive and respiratory syndrome (PRRS) continues to be a significant problem for European pig producers, contributing to porcine respiratory disease complex, neonatal piglet mortality, infertility and occasional abortion storms. PRRS virus (PRRSV), a member of the arterivirus family with two defined major genotypes, has been shown to be quite genetically diverse. In the present study, genetic analysis of multiple gene regions of over 100 viruses isolated in Britain between 2003 and 2007 revealed that the diversity of British strains is now far greater than during the early 1990s. All isolates belong to genotype 1 (European). While some recent isolates are still very similar to early isolates, a wide range of more diverse viruses is now also circulating. Interestingly, some isolates were found to be very similar to a modified-live vaccine strain, and it is suggested that use of the vaccine has affected the evolution pattern of PRRS virus strains in Britain. Evidence of deletions in one viral gene, ORF3, and of genome recombination was also seen. A molecular clock model using the ORF7 sequences estimates the rate of substitution as $3.8 \times 10^{-3}$ per site per year, thereby dating the most recent common ancestor of all British viruses to 1991, coincident with the first outbreak of disease. Our findings therefore have implications for both the diagnostic and prophylactic methods currently being used, which are discussed.
\end{abstract}

Crown Copyright (c) 2012 Published by Elsevier B.V. All rights reserved.

\section{Introduction}

Porcine reproductive and respiratory syndrome (PRRS) was first described in the United States of America in 1987 (Keffaber, 1989), and subsequently in Europe in 1990 (Wensvoort et al., 1991). The causative agent, PRRS virus

\footnotetext{
is The GenBank accession numbers for the new sequences described are listed in supplementary table.

* Corresponding author. Tel.: +44 01932 357281;

fax: +4401932 357239

E-mail addresses: Jean-Pierre.Frossard@ahvla.gsi.gov.uk, j.frossard@vla.defra.gsi.gov.uk (J.-P. Frossard).

${ }^{1}$ Current address: Health Protection Services, Health Protection Agency, Institute of Public Health, Cambridge CB2 OSR, United Kingdom.
}

(PRRSV), is a single-strand positive-sense RNA virus of the order Nidovirales, family Arteriviridae (Rossow, 1998). The disease remains a significant problem worldwide, with a considerable economic impact for affected producers, due to increased mortality, treatment costs, and reduced weight gain and fertility (Neumann et al., 2005). More pathogenic variants have been described in the past, and since 2006, a highly pathogenic form of the virus has been circulating in China and other parts of Asia, causing a devastating economic impact (Zhou et al., 2008).

The mode of replication of the virus makes it prone to high rates of mutation and recombination (Gorbalenya et al., 2006). A high degree of diversity in the virus population has recently been reported in the United States (Fang et al., 2007), China (Li et al., 2009), Spain (Mateu 
et al., 2006; Prieto et al., 2009), and eastern Europe (Stadejek et al., 2008). Despite the apparent increase in the number of cases of PRRS in Great Britain, little information has been available regarding the virus population since 1995 (Drew, 1996). Here, the geographical characteristics of Britain as an island, the licensed use of only one type of modified live vaccine, and the international trade conditions with limited import of live pigs into the country, argue for a relatively isolated evolutionary situation.

In this study, we aimed to obtain a comprehensive picture of the current diversity of PRRSV strains circulating in pig herds, using multiple gene regions, and compare this to the previous analysis with samples from the early 1990 s. The strains analysed were obtained by virus isolation rather than molecular detection, thus avoiding any potential bias introduced by the choice of amplification primers.

\section{Materials and methods}

\subsection{Virus isolation}

PRRS viruses were isolated from clinical material (tissues or serum) submitted for PRRS diagnosis, using PRRS-free primary porcine alveolar macrophages (PAMs), labelled with monoclonal antibody SDOW17 (Nelson et al., 1993), and visualised by immunoperoxidase staining (Wensvoort et al., 1992). One hundred virus isolates from individual pigs from 62 farms were thus obtained for analysis between 2003 and 2008. These included 23 isolates from a targeted investigation of finisher pigs, described elsewhere (Jackson et al., 2006). Corresponding case histories and herd vaccination records were available.

\subsection{Sequence analysis}

Nucleic acid was extracted using the QIAamp ${ }^{\circledR}$ Viral RNA Mini Kit (QIAGEN), and used to generate cDNA using random primers and SuperScript ${ }^{\mathrm{TM}}$ II reverse transcriptase (Invitrogen). The cDNA was then used in PCR amplifications using primers specific for viral genes as described in
Table 1. For nucleotide sequencing, the amplification products were purified using the QIAquick ${ }^{\circledR}$ gel extraction kit (QIAGEN). The Sanger sequencing reaction was performed using BigDye chemistry. The sequence data was analysed and assembled using SeqMan software version 7.1.0 (Lasergene, DNASTAR). Alignment of the sequences for comparison was performed with the ClustalW algorithm (Thompson et al., 1994), using MEGA software version 3.1 (Kumar et al., 2004). Phylogenetic and molecular evolutionary analyses (neighbour-joining method with bootstrap test) were conducted using MEGA software version 3.1. Predicted RNA folding patterns were investigated using mfold software (Mathews et al., 1999; Zuker, 2003).

Estimation of nucleotide substitution rates and timescaled phylogenies were generated using BEAST v1.4.3 (Drummond and Rambaut, 2007). A model of the relaxed molecular clock was used as this has been shown to provide a better fit to viral sequence data (Drummond et al., 2006). Modelling was performed using the HKY85 model of nucleotide substitution with a gamma distribution of rate variation. Two separate runs of chain length $1 \times 10^{7}$ were combined to provide an effective sample size $>200$ for all parameters. After a burn-in of $10 \%$ runs were combined to generate maximum clade credibility trees from a sample of 18,000 trees.

\section{Results}

In total, nucleotide sequence data was obtained from 147 recent virus isolates and 16 isolates from the 1990s. The ORF7 and ORF5 regions were examined initially, but later only ORF5, and for strains considered to be of particular interest, further regions were subsequently analysed, providing a total of 108 ORF7, 14 ORF6, 120 ORF5, 17 ORF4, and 54 ORF3 complete sequences. Where multiple isolates were available from the same farm, either from one time-point or several, the levels of similarity varied greatly, with some isolates having near-identical gene sequences, and others being radically different. Where duplicate or similar sequences were identified

Table 1

Oligonucleotide primers used for sequencing isolates of PRRS virus.

\begin{tabular}{|c|c|c|c|}
\hline Primer & Position $^{\mathrm{a}}$ & Gene target & Sequence $^{\mathrm{b}}$ \\
\hline ORF3_Fwd ${ }^{\mathrm{c}}$ & $12,365-12,383$ & ORF3 & CACGCCAGGTACCAGGCCA \\
\hline ORF3_Rev ${ }^{\mathrm{c}}$ & $13,236-13,255$ & ORF3 & AAAGCATCTGCAGGTCCGCG \\
\hline 12500_Fwd & $12,500-12,519$ & ORF3 & TGTTTTTGGTTTCCATTGGC \\
\hline 12904_Rev & $12,904-12,927$ & ORF3 & CCCCCGTCTATTTGGTGGTGGTAA \\
\hline ORF4_Fwd ${ }^{\mathrm{c}}$ & $12,926-12,945$ & ORF4 & GGCAATTGGATCCATTTGGA \\
\hline ORF4_Rev ${ }^{\mathrm{c}}$ & $13,526-13,545$ & ORF4 & AGAAGCAAGCTTGCGGAGTC \\
\hline 13187_Fwd & $13,187-13,210$ & ORF5 & AGTACATCACGATAACGGCTAACG \\
\hline ORF5_Fwd & $13,446-13,465$ & ORF5 & GAGGTGGGATCCAACATTG \\
\hline ORF5_Rev ${ }^{c}$ & $14,125-14,144$ & ORF5 & CTAGCACAAGCTTTTGTGCG \\
\hline ORF6_Fwd & $14,061-14,080$ & ORF6 & CCCTTGACGAGCTCTTCGGC \\
\hline ORF6_Rev ${ }^{\mathrm{c}}$ & $14,630-14,649$ & ORF6 & CCATCGGATCCGTACTTTTC \\
\hline $\mathrm{P} 71^{\mathrm{d}}$ & $14,564-14,582$ & ORF7 & GCTGTTAAACAGGGAGTGG \\
\hline $\mathrm{P} 72^{\mathrm{d}}$ & $15,029-15,049$ & ORF7 & CGCCCTAATTGAATAGGTGAC \\
\hline ORF7_Fwd ${ }^{\mathrm{c}}$ & $14,581-14,600$ & ORF7 & GGTTAACCTCGTCGACTATG \\
\hline
\end{tabular}


from isolates originating from the same farm, only one representative sequence was included in the percentage similarity analyses. The GenBank accession numbers are listed in supplementary table. Comparisons were made with published ORF7 and ORF5 nucleotide sequences from around the world (256 ORF7 and 458 ORF5).

Supplementary data associated with this article can be found, in the online version, at http://dx.doi.org/10.1016/ j.vetmic.2012.11.011.

\subsection{ORF7}

Ninety-two recent isolates, 16 isolates from the 1990s, and the prototype Lelystad virus were compared for the ORF7 sequence analysis. All sequences were 387 base pairs long, encoding the complete 128 amino acid long nucleocapsid protein. The nucleocapsid is the most abundant viral protein, is immunogenic, and is thought to be multifunctional, locating to the nucleus of infected cells as well as the cytoplasm (Snijder and Meulenberg, 1998). The degree of nucleotide identity ranged from $100 \%$ to $86.9 \%$ ( $n=65$, mean $94.1 \%$ ). This compares to a range from $100 \%$ to $97.9 \%$ (mean 99.1\%) when examining only the 1990s isolates.

Analysing the specific nucleotide changes seen, 237 of the 387 nucleotide positions remained unchanged in any isolate. Of the positions that did vary, 88 featured synonymous substitutions, while 62 featured non-synonymous substitutions. The total number of synonymous changes was 900 , versus 488 non-synonymous changes.

A phylogenetic tree showing the relationship of British isolates compared to 468 other worldwide isolates is shown in Fig. 1A. Further analysis of the relationship between all of the British isolates and the Lelystad European reference virus underlines the increased variability currently observed (Fig. 2A), whereas strains analysed early after the first detection of PRRSV in Britain (including the British reference strain $\mathrm{H} 2$ ) all cluster closely with the Lelystad prototype virus, the first European isolate described (Wensvoort et al., 1991). In addition to the clades containing almost entirely British isolates, some contain sequences derived from other countries in western Europe including Belgium, France, Germany, Hungary, Poland, Spain and the Netherlands. A minority of British isolates are grouped apart from the rest, one being clustered with a sequence from Spain (DQ057992), one with sequences from Spain and Serbia (GQ451688 and GU930382), and five being clustered with sequences from Austria and Hungary (GU930373 and GU930369). None of the British sequences fall within the divergent eastern European subgroups.

Examining the deduced amino acid sequences, 80 of the 128 positions were conserved in all of the isolates.
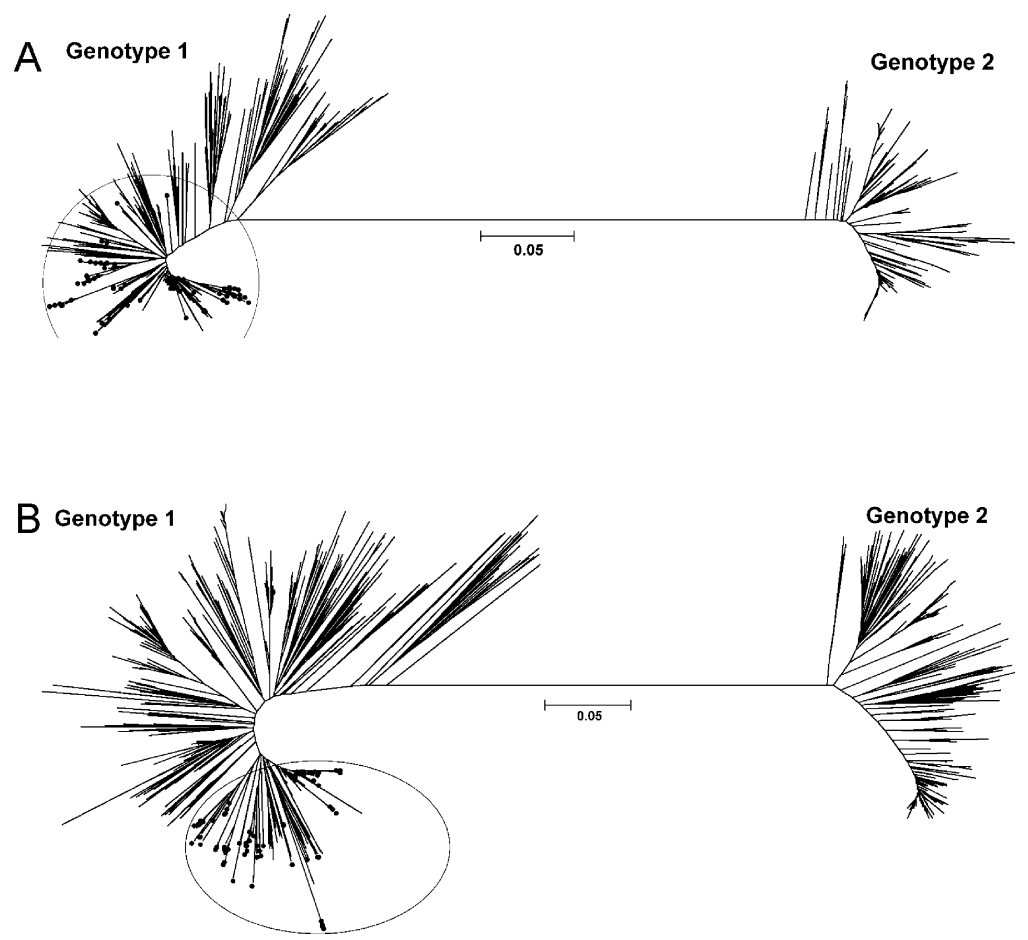

Fig. 1. Phylogenetic analysis of PRRSV nucleotide sequences as indicated. Alignment of the sequences was performed with the ClustalW algorithm, and phylogenetic analyses (neighbour-joining method with bootstrap test, 1000 replicates) were conducted using MEGA software version 3.1. The scale bar represents five nucleotide changes per hundred. Genotype 2 (North American) is found in North America, Asia, and Scandinavia, and now in some other parts of Europe. The highly pathogenic Asian viruses form a small cluster in this genotype. Genotype 1 (European) viruses are found in Europe, but also in Asia and North America, again in clusters forming at least three distinct subtypes. The ORF5 gene clearly shows more variability than the ORF7 gene. Based on the ORF5 analysis, all of the British isolates analysed share one presumed common ancestor, whereas the ORF7 analysis suggests multiple introductions of PRRSV into Britain are likely. (A) ORF7 nucleotide sequences from 92 recent British isolates, 16 British isolates from the 1990 s, and 468 Worldwide isolates. The British sequences are indicated by black circles. (B) ORF5 nucleotide sequences from 105 recent British isolates, 15 British isolates from the 1990s, and 751 Worldwide isolates. 


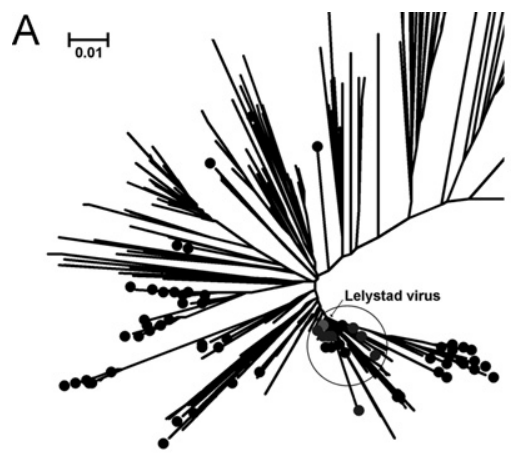

B
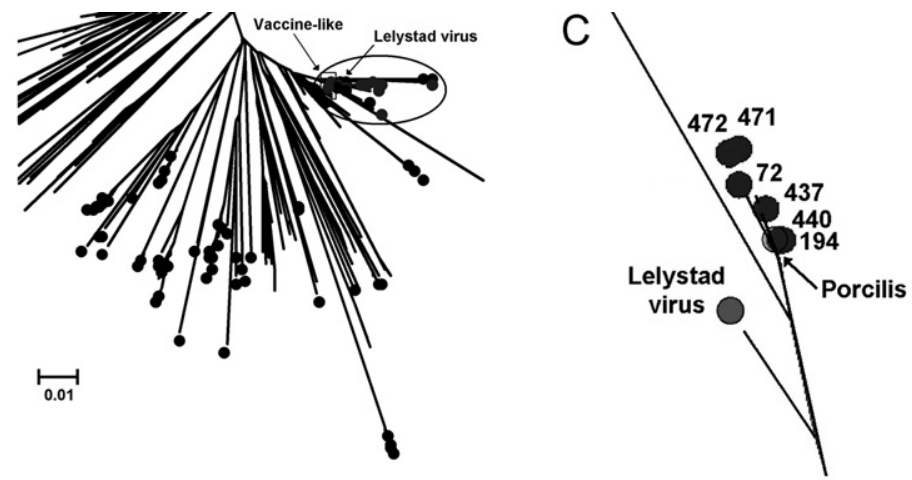

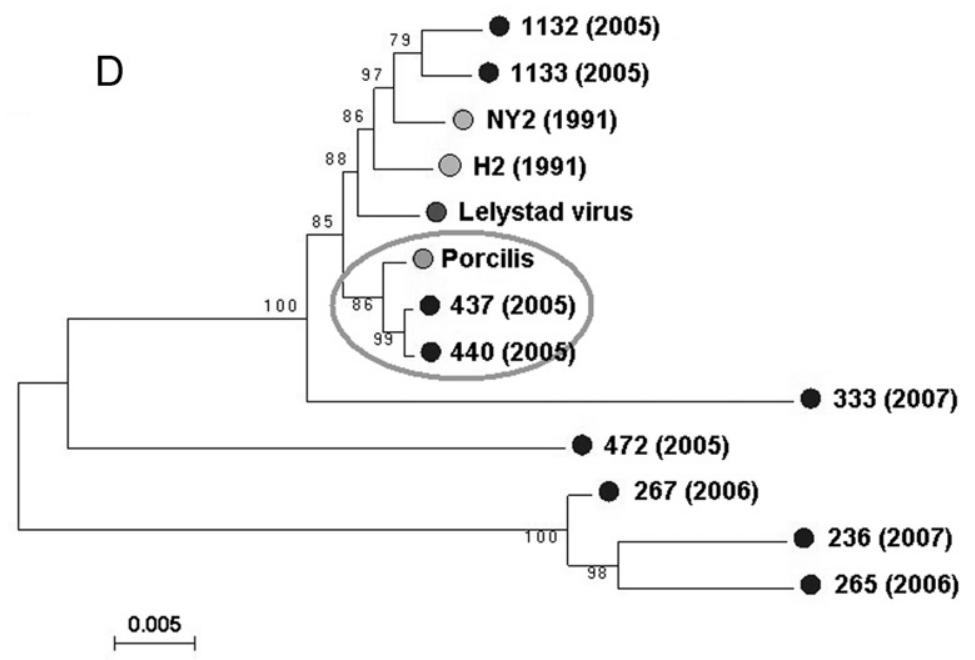

Fig. 2. Phylogenetic analysis of PRRSV nucleotide sequences as indicated. Alignment of the sequences was performed with the ClustalW algorithm, and phylogenetic analyses (neighbour-joining method with bootstrap test) were conducted using MEGA software version 3.1. The scale bar represents one nucleotide change per hundred ( $A$ and B) or 5 changes per thousand (D). The circled areas show the close relationship of all the 1990s isolates, compared to the diversity of the more recent viruses. The rectangle in the ORF5 analysis shows a cluster of vaccine-like isolates. (A) ORF7 nucleotide sequences from 92 recent and 16 1990s British isolates (all designated with black circles) and the Lelystad reference strain, in context with other published genotype 1 sequences. The sequence for the Lelystad virus is the same as for several early UK isolates. (B) ORF5 nucleotide sequences from 105 recent and 151990 s British isolates (all designated with black circles) and the Lelystad reference strain, in context with other published genotype 1 sequences. (C) The close-up from the ORF5 analysis shows the considerable similarity of six recent field isolates to the vaccine strain. (D) Nucleotide sequences spanning the ORF3 to ORF7 region (2581 nucleotides) from 9 recent British isolates, two British isolates from the 1990s, the Lelystad reference strain, and the Porcilis vaccine strain. The circled area shows the close relationship of two isolates and the vaccine strain. Isolates NY2, 236, 265, 267, 333, 1132, and 1133 are included in the analysis as outgroups for comparison with the vaccine-like and reference isolates.

Twenty-nine positions varied in more than one isolate, and 14 positions varied in more than 10 isolates. Both cysteine residues (positions 27 and 76), thought to be the crucial for homodimer formation of the nucleocapsid were conserved in all isolates, as was the putative nonapeptide linear B cell epitope (positions 80-88) described previously (An et al., 2005). Fig. 3 shows a summary of the consensus sequence, conserved residues, and substitution rates. The degree of amino acid identity ranged from $100 \%$ to $84.5 \%$ ( $n=65$, mean 93.9\%). This compares to a range from $100 \%$ to $93.5 \%$ (mean $98.9 \%$ ) when examining only the 1990 s isolates.

\subsection{ORF5}

A total of 105 recent isolates, 15 isolates from the 1990s, and the Lelystad virus were compared with regard to the ORF5 sequence. All sequences were 606 base pairs long, encoding the complete 201 amino acid long major envelope glycoprotein (GP5), which is essential for virion assembly (Snijder and Meulenberg, 1998). The degree of similarity ranged from $100 \%$ to $82.0 \%$ ( $n=83$, mean $91.7 \%$ ). This compares to a range from $100 \%$ to $96.4 \%$ (mean $97.8 \%$ ) when examining only the 1990s isolates.

The global analysis including 751 other published sequences shows that the gene for GP5 is more diverse than that for the nucleocapsid (Fig. 1B). All British isolates clearly fall within genotype 1 (European), but are distinct from the recently described eastern European subgroups. Since the 1990s British viruses have evolved so much that they now form a wide diverse clade, rather than a discrete cluster, such as was seen for the early British isolates (Fig. 2B) and the recent highly pathogenic isolates from Asia. The global topology suggests that all of the British isolates have a single predicted common ancestor, possibly 
A
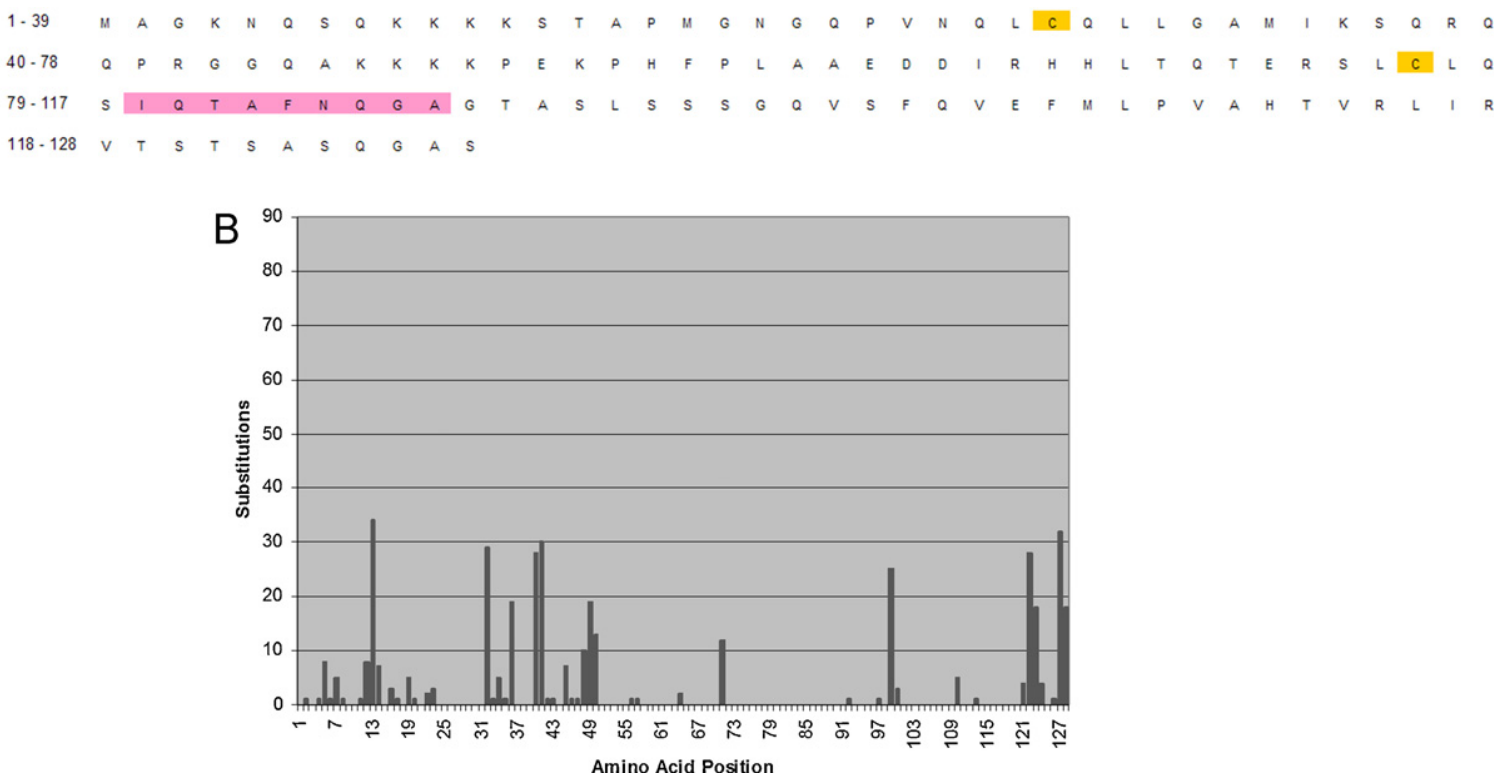

Fig. 3. (A) Amino acid consensus sequence for the nucleocapsid protein, derived from 92 recent PRRSV isolates from Britain. Conserved cysteine residues are highlighted in orange. The conserved putative linear B cell epitope is highlighted in pink. (B) Histogram showing the number of substitutions found at each position, from the 92 recent isolates. 80 of the 128 positions were conserved in all of the isolates, while 29 positions varied in more than one isolate, and 14 varied in more than 10 isolates. Both cysteine residues (positions 27 and 76) thought to be the crucial for homodimer formation of the nucleocapsid were conserved in all isolates, as was the putative nonapeptide linear B cell epitope (positions 80-88) described previously. (For interpretation of the references to color in this figure legend, the reader is referred to the web version of the article.)
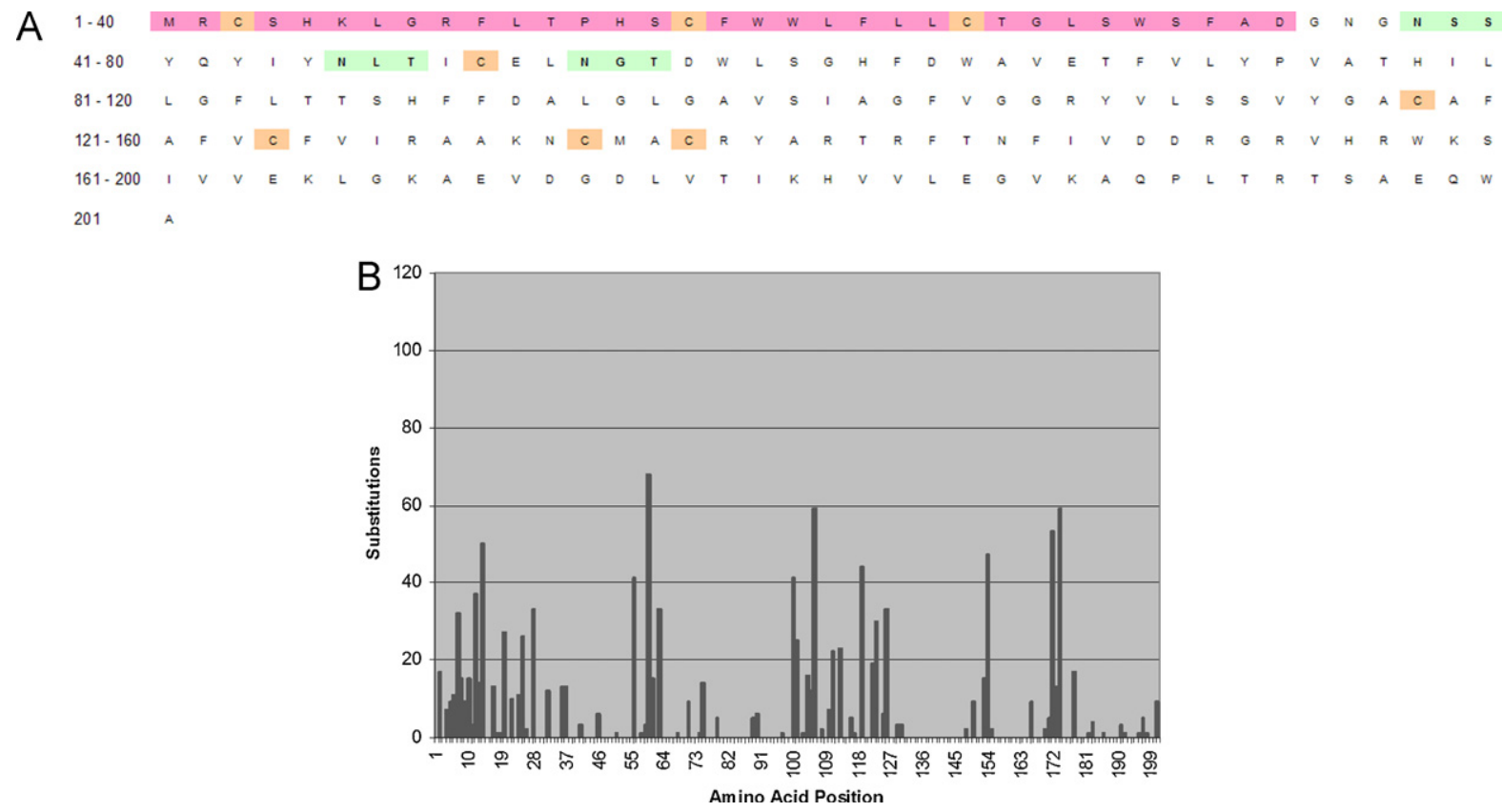

Fig. 4. (A) Amino acid consensus sequence for the GP5 envelope protein, derived from 105 recent isolates. The conserved cysteine residues are highlighted in orange. The three putative N-glycosylation sites are highlighted in green. The predicted signal peptide sequence is highlighted in pink. (B) Histogram showing the number of substitutions found at each position, from the 105 recent isolates. 120 of the 201 positions were conserved in all of the isolates, 67 positions varied in more than one isolate, and 38 positions varied in more than 10 isolates. 7 cysteine residues (positions 3, 16, 50, 117, 124, 133 and 136), thought to be the involved in heterodimer formation with the M protein, were conserved in all isolates, and an eighth (position 24) was not conserved in 11 isolates. The putative signal peptide sequence (positions 1 to 33) was conserved in all isolates. Putative $\mathrm{N}$-glycosylation sites varied, with one (positions $53-$ 55) being conserved in all isolates, one (positions 46-48) being conserved in all but 6 isolates, and one (positions 37-39) being conserved in all but 13 isolates. (For interpretation of the references to color in this figure legend, the reader is referred to the web version of the article.) 

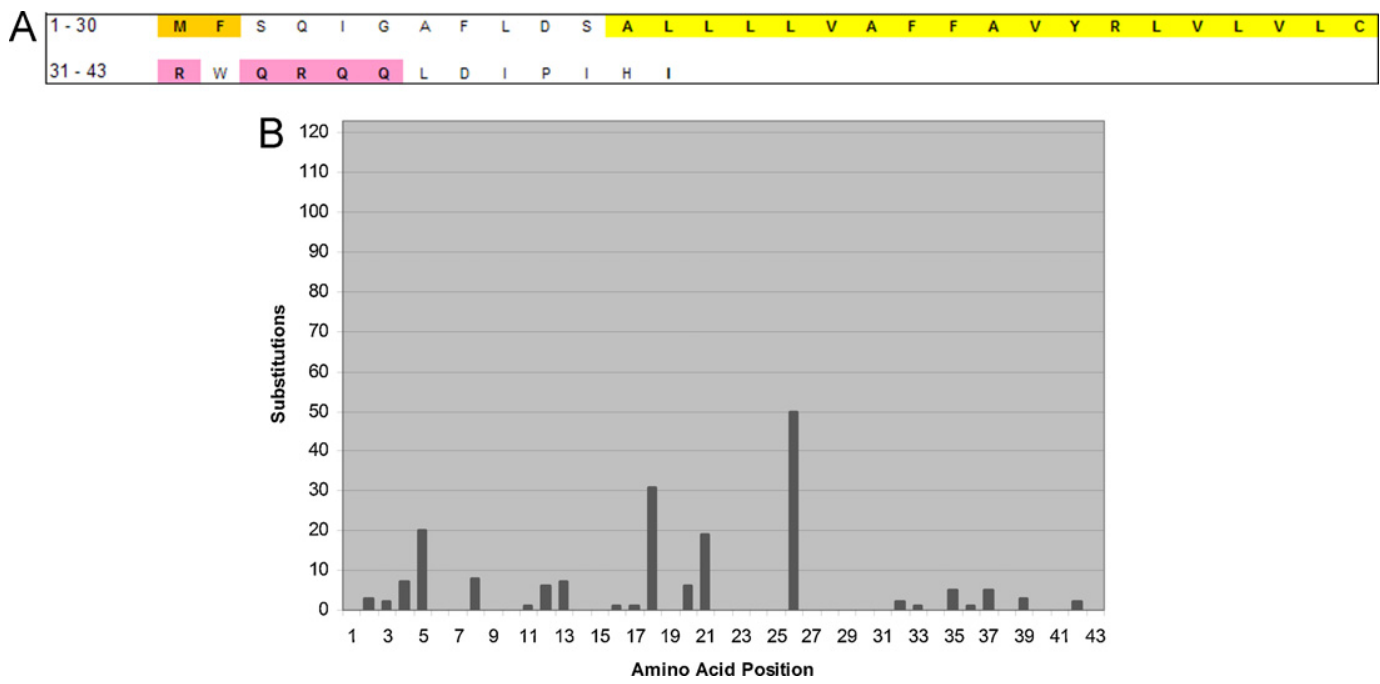

Fig. 5. (A) Amino acid consensus sequence for the ORF5a protein, derived from 123 recent isolates. The conserved amino-terminal methionine and phenylalanine residues are highlighted in orange. The putative transmembrane domain is highlighted in yellow. The conserved endodomain arginine and glutamine residues are highlighted in pink. (B) Histogram showing the number of substitutions found at each position, from the 123 recent isolates. 22 of the 43 positions were conserved in all of the isolates, 16 positions varied in more than one isolate, and 4 positions varied in more than 10 isolates. The conserved amino-terminal methionine and phenylalanine residues described for the ORF5a of all arteriviruses were maintained, except for a phenylalanine to leucine substitution in three isolates. The putative transmembrane domain contains well conserved regions and some highly variable regions (positions 18,21 and 26). The endodomain arginine and glutamine rich region was well conserved, with a glutamine to arginine substitution at positions 35 or 36 in four isolates, and a glutamine to lysine substitution at position 33 in two isolates. (For interpretation of the references to color in this figure legend, the reader is referred to the web version of the article.)

representing a single early introduction into the country. The grouping also includes sequences derived from Austria, Germany, Spain and The Netherlands.

Examining the deduced amino acid sequences, 120 of the 201 positions were conserved in all of the isolates. Sixty-seven positions varied in more than one isolate, and 38 positions varied in more than 10 isolates. Seven cysteine residues (positions 3, 16, 50, 117, 124, 133 and 136), thought to be the involved in heterodimer formation of GP5 with the M protein, were conserved in all isolates (therefore likely to be crucial), and an eighth (position 24) was conserved in all but 11 isolates (therefore considered not crucial). The putative signal peptide sequence (positions 1-33) was conserved in all isolates. Putative Nglycosylation sites varied, with one (positions 53-55) being conserved in all isolates (therefore likely to be essential), one (positions 46-48) being conserved in all but 6 isolates, and one (positions 37-39) being conserved in all but 13 isolates (Fig. 4).

\subsection{ORF5a}

A total of 123 recent isolates and 12 isolates from the 1990s were compared with regard to the ORF5a sequence. All sequences were 132 base pairs long, encoding the complete 43 amino acid long protein recently described (Firth et al., 2011; Johnson et al., 2011). The degree of nucleic acid similarity ranged from $100 \%$ to $82.5 \%$ (mean $94.2 \%$ ). This compares to a range from $100 \%$ to $96.1 \%$ (mean $98.6 \%$ ) when examining only the 1990 s isolates.

Examining the deduced amino acid sequences (see Fig. 5), 22 of the 43 positions were conserved in all of the isolates. Fifteen positions varied in more than one isolate, and four positions varied in more than 10 isolates. The majority of isolates featured the conserved amino-terminal MF sequence and the $\mathrm{R} / \mathrm{Q}$ rich motif near the carboxyl terminus (Johnson et al., 2011). The cysteine residue at position 30 was maintained in every isolate. A putative transmembrane domain (Firth et al., 2011) spanning positions $12-30$ is well conserved overall, with hypervariable amino acids at positions 18 and 26.

\subsection{ORF3}

A total of 40 recent isolates, 14 isolates from the 1990s, and the Lelystad virus were included in the analysis of the ORF3, coding for GP3, a minor envelope glycoprotein, whose function is not resolved (Snijder and Meulenberg, 1998). Interestingly, the sequences varied in length from 723 to 798 base pairs long, making the resulting envelope glycoprotein between 240 and 265 amino acids long. When counting each deletion as a substitution, the degree of nucleotide identity ranged from $100 \%$ to $85.0 \%(n=27$, mean $92.0 \%$ ). This compares to a range from $100 \%$ to $95.2 \%$ (mean 98.5\%) when examining only the 1990s isolates, all of which were 798 nucleotides long. Analysing the deduced amino acid sequences, 170 of the 265 positions were conserved in all of the isolates. Eighty-four positions varied in more than one isolate, and 31 positions varied in more than 10 isolates. Seven cysteine residues (positions $17,33,54,57,75,82$ and 144) were conserved in almost all isolates, and two more (positions 5 and 13) were conserved in all but 6 isolates. The putative signal peptide sequence was identified (positions 1-22) in all isolates. Putative 

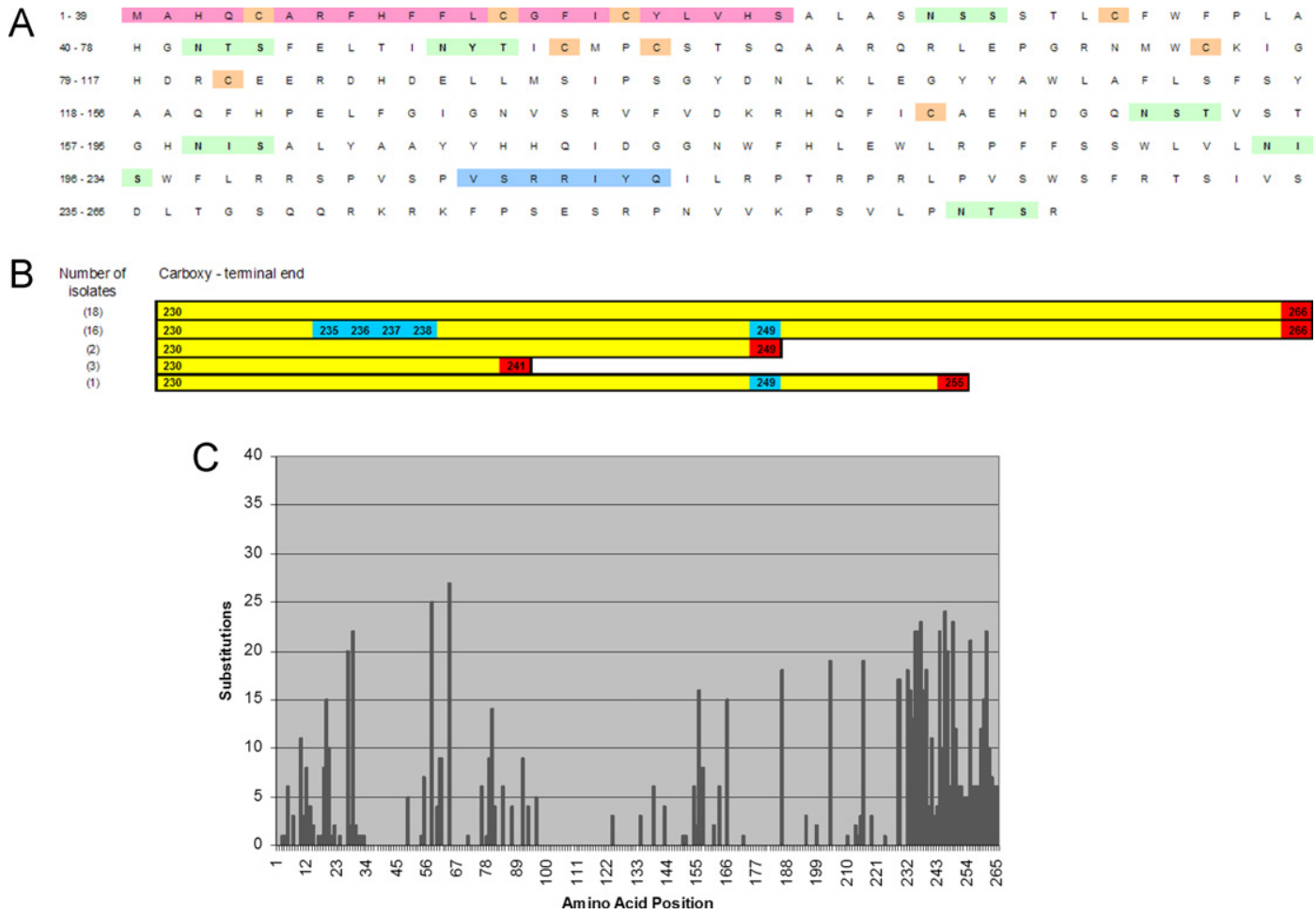

Fig. 6. (A) Amino acid consensus sequence for the GP3 envelope protein, derived from 40 recent isolates. The conserved cysteine residues are highlighted in orange. The putative $\mathrm{N}$-glycosylation sites are highlighted in green. The predicted signal peptide sequence is highlighted in pink. The conserved repeat sequence also found in ORF2 is highlighted in blue. (B) GP3 envelope protein carboxy-terminal structure (from position 230 to the end) of the 40 recent isolates, showing deletions in blue, and termination sites in red. (C) Histogram showing the number of substitutions found at each position (where deletions or positions downstream of the termination site are counted as a substitution), from the 40 recent isolates. 170 of the 265 positions were conserved in all of the isolates, 84 positions varied in more than one isolate, and 31 varied in more than 10 isolates. 7 cysteine residues (positions 17, 33, 54, 57, 75, 82 and 144) were conserved in almost all isolates, and two more (positions 5 and 13) were conserved in all but 6 isolates. The putative signal peptide sequence was present (positions 1-22) in all isolates. Putative N-glycosylation sites varied, with 5 (positions 42-44, 50-52, 151-153, 159-161, and 194-196) being conserved in all isolates, 1 (positions 262-264) being conserved in all but 10 isolates, and 1 (positions 27-29) being conserved in all but 20 isolates. A 7 residue repeat motif (positions 207-213) of unknown function, but also normally found in ORF2, was conserved in all isolates. 4 different patterns of deletion and early termination variants were found: 1 featured a single amino acid deletion (position 249) and terminated at position 256.16 isolates featured a 5 amino acid deletion (positions 235-238, and 249). Finally, 3 isolates terminated at position 241, and 2 terminated at position 249, all without any deletions. (For interpretation of the references to color in this figure legend, the reader is referred to the web version of the article.)

$\mathrm{N}$-glycosylation sites varied, with five (positions $42-44$, 50-52, 151-153, 159-161, and 194-196) being conserved in all isolates, one (positions 262-264) being conserved in all but 10 isolates, and one (positions 27-29) being conserved in all but 20 isolates. A seven residue repeat motif (positions 207-213) of unknown function, but also normally found in ORF2 (Oleksiewicz et al., 2002), was conserved in all isolates. Four different patterns of deletion and early termination variants were found. One featured a single amino acid deletion (position 249) and terminated at position 256. Sixteen isolates featured a 5 amino acid deletion (positions 235-238, and 249). All of the deletions are in the area of overlap with ORF4, so the GP4 protein size is likely to also be affected in these 17 isolates. Finally, three isolates terminated at position 241 , and two terminated at position 249 , all without any deletions. Fig. 6 shows a summary of the consensus sequence, conserved residues, deletions, and substitution rates.

\subsection{Vaccine-like isolates}

The phylogenetic analysis of ORF5 nucleotide sequence data revealed a group of six virus isolates which were very similar ( $>99.2 \%$ similarity) to the live vaccine strain used in Britain (see Fig. 2C). Additional sequencing across ORF4 and ORF6 showed that two of the isolates had a $99.6 \%$ and $99.7 \%$ similarity with the vaccine strain sequence over the entire region of the genome from ORF3 to ORF7 (2581 nucleotides), while a third isolate (472-05) showed only a $94.4 \%$ similarity overall, despite $99.5 \%$ similarity in the ORF5 region (Fig. 2D). Further analysis of the sequence from this isolate suggests that it probably results from a double recombination event between a diverse field strain of PRRSV and the vaccine strain or a "vaccine-like" strain. Fig. 7A shows an alignment of the sequences from this isolate and the vaccine strain, highlighting the likely areas of recombination. Examination of the region surrounding ORF5 in the two viruses revealed the presence of 
A

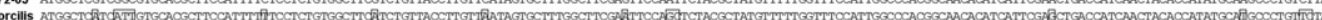

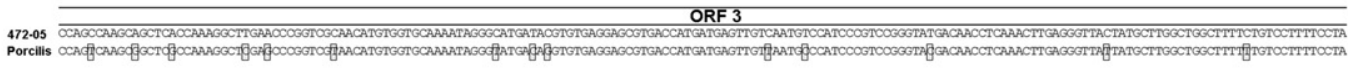

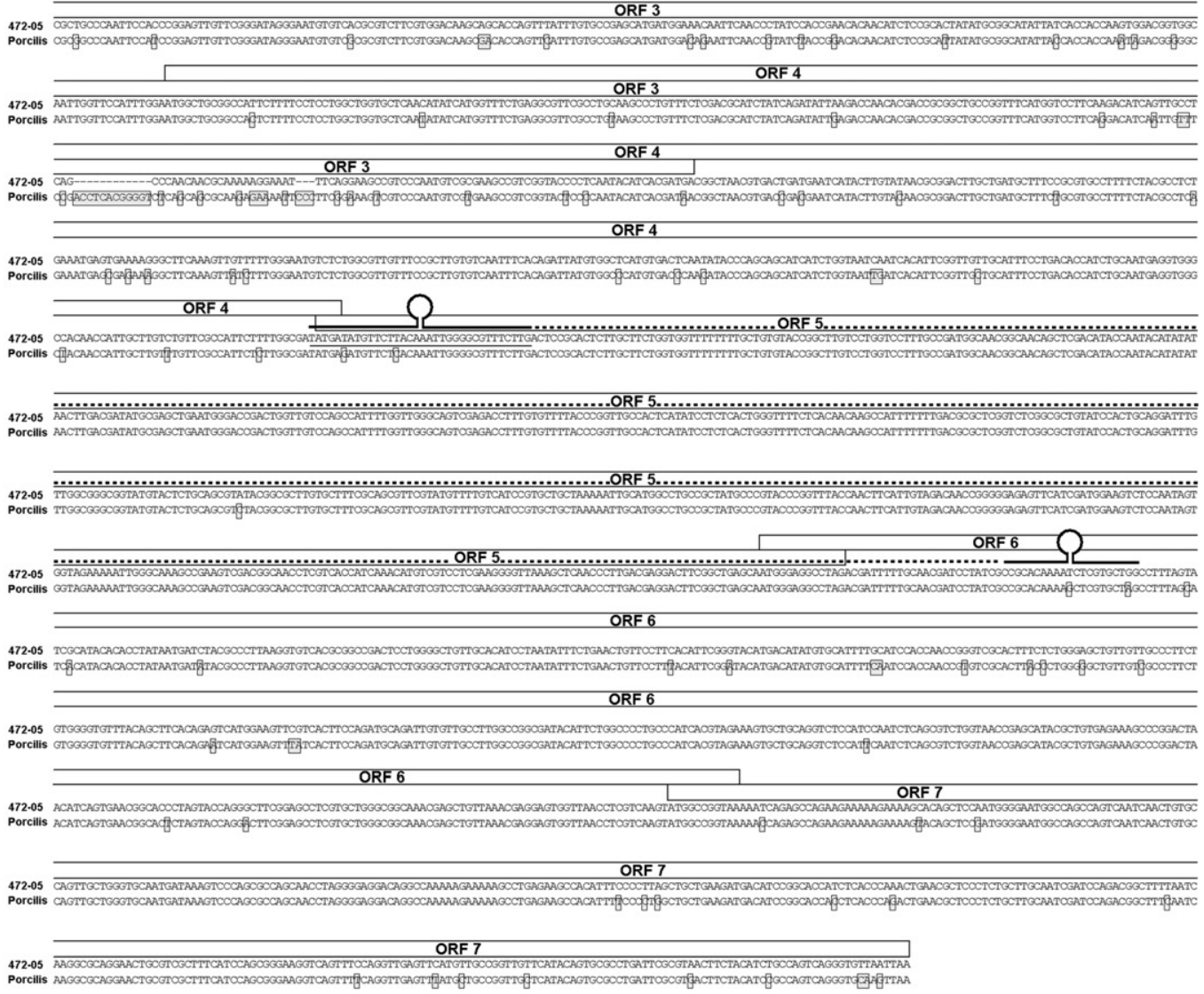

B

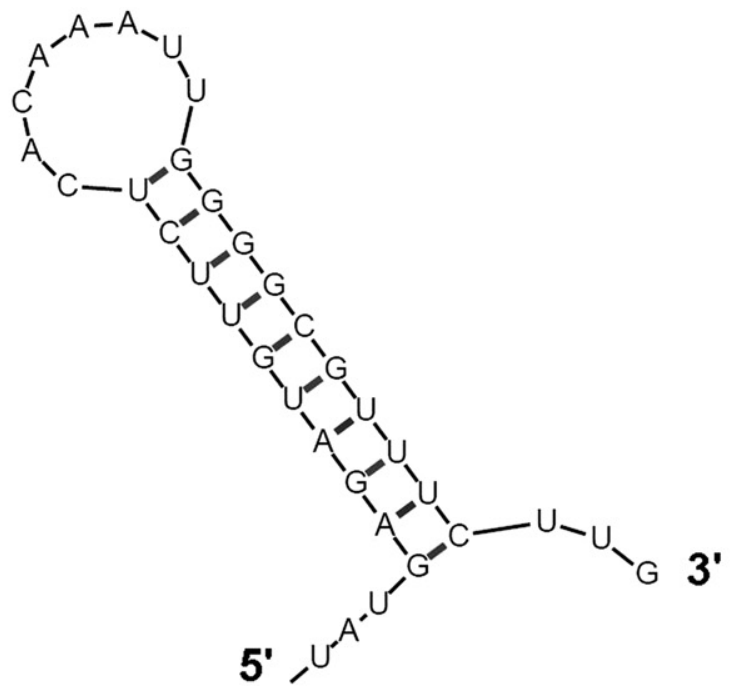

3'

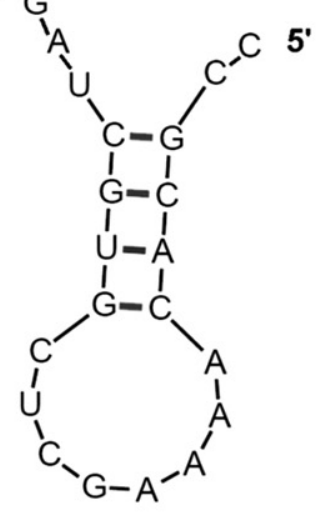

Fig. 7. (A) ClustalW alignment of the nucleotide sequences spanning the ORF3-ORF7 region (2581 nucleotides) from the Porcilis vaccine virus and field isolate $472-05$, with mismatches in the Porcilis sequence boxed. The putative recombination site is shown by a thick dashed line, essentially comprising the entire ORF5 region, where it is suggested that the field virus acquired vaccine or vaccine-like genetic material, and a second recombination event occurred, replacing the $3^{\prime}$ end of the genome with the original, or another, field virus. The position of predicted stem-loop structures surrounding the recombination sites is indicated. (B) The two predicted stem-loop structures flanking the recombination sites are shown at the nucleotide level. 


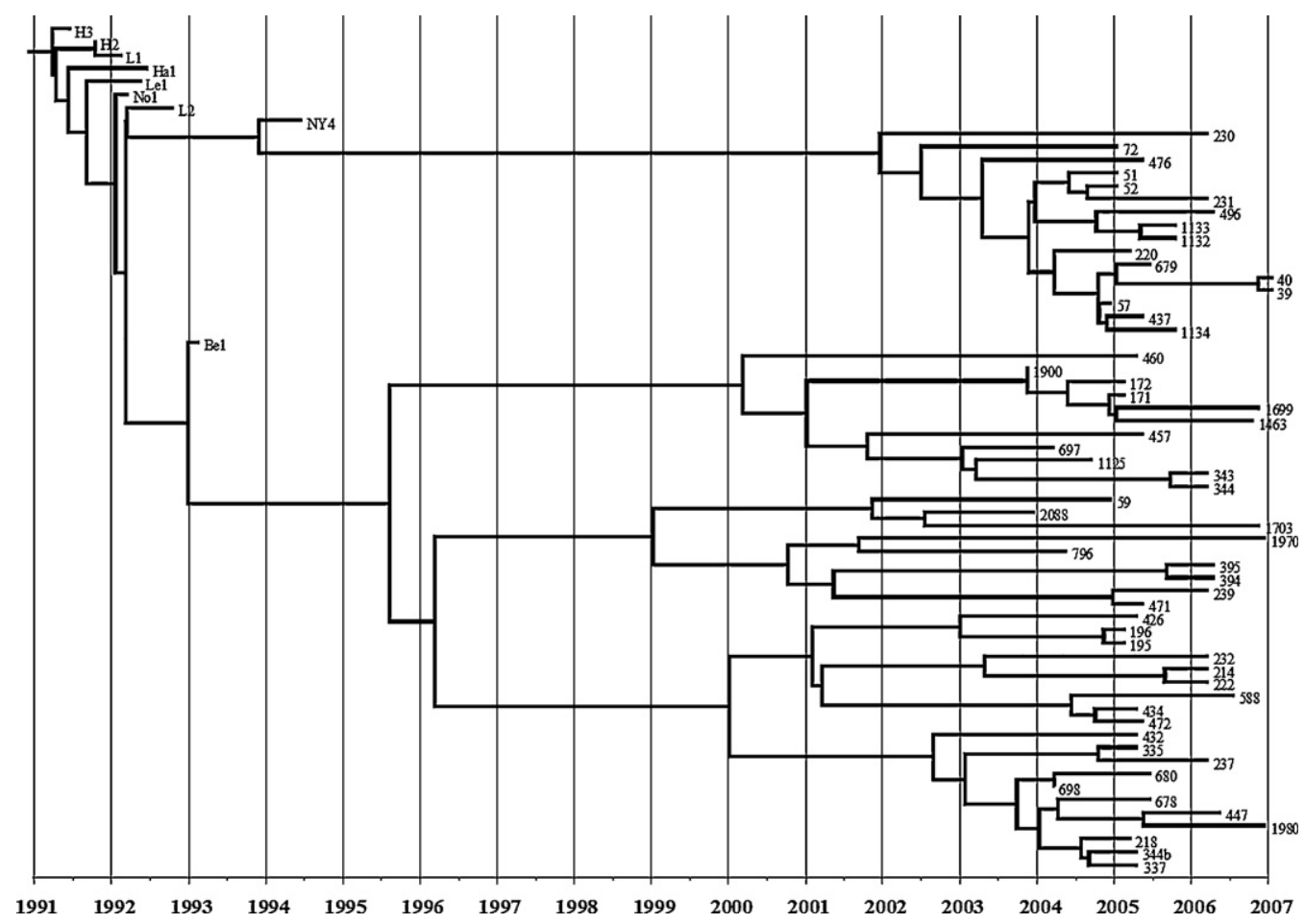

Fig. 8. Time-scaled maximum clade credibility tree generated using a relaxed molecular clock for ORF7 sequences of 56 recent and 9 earlier (1990s) UK isolates.

28-nucleotide and 16-nucleotide sequences which can adopt a stem-loop structure, flanking the putative recombination site (see Fig. 7B). These may represent recombination "hotspots", where the hairpin initiates dissociation of the RNA-dependent RNA polymerase complex, allowing a subsequent template switch.

\subsection{Application of a relaxed molecular clock}

The analysis of ORF7 and ORF5 suggested predominantly a single incursion of PRRSV into Britain. The alignment of ORF7 sequences (including 9 British isolates from the 1990s) was used to estimate the substitution rate for this gene using a relaxed molecular clock (Drummond et al., 2006). The substitution rate was estimated as $4.0 \times 10^{-3}$ (95\% highest probability distribution [HPD]: $2.6 \times 10^{-3}$ to $5.4 \times 10^{-3}$ ), corresponding to a time of the most recent common ancestor (tMRCA) for the entire phylogeny as occurring in 1991 (95\% HPD: 1988-1993) (Fig. 8).

\section{Discussion}

The recent emergence of highly pathogenic strains of PRRS virus in North America (Han et al., 2006) and especially in Asia (Li et al., 2007; Normile, 2007; Tian et al., 2007; Tong et al., 2007), as well as reports of greater pathogenicity associated with at least one eastern European virus (Karniychuk et al., 2010; StockhofeZurwieden et al., 2011), has highlighted the potential for ongoing changes in the virus to result in highly pathogenic mutants. This demonstrates a need to monitor the evolution of existing virus strains in order to detect the emergence of any with such an increased virulence. It also highlights the need to review the efficiency of diagnostic tests designed to detect PRRS virus and antibody, as well as the potential efficacy of vaccines.

During the period from 2003 to 2008, 147 distinct PRRS viruses were isolated from clinical material submitted from confirmed or suspected outbreaks of PRRS in Britain. To date, no significant correlation of genotype 1 PRRS virus isolates has been found relating to disease severity. Also in this study, virulence did not cluster in particular clades of the viruses, nor was any significant grouping found relating to disease presentation (respiratory versus reproductive).

While using virus isolation rather than molecular detection to select samples for analysis avoided any potential bias due to the choice of amplification primers, it added other restrictions such as requiring the presence of viable virus able to propagate in the cells used. Due to the technical difficulty in isolating virus from reproductive disease outbreaks, isolates from respiratory disease were over-represented in this study. The use of a single monoclonal antibody to identify PRRSV in culture is another potential restriction on the diversity observed. The antibody SDOW17 binds to a well-conserved epitope of the nucleocapsid protein, located between amino acid positions 18 and 52 (Wootton et al., 1998). However, at least two genotype 2 PRRS isolates so far described (one field and one vaccine) do not react with this antibody (Yoon et al., 1995; Nelson et al., 1997). However, no 
genotype 1 viruses have thus far been described which this antibody does not recognise.

Specific nucleotide sequence data was obtained from various regions of the virus genomes, starting with ORF7 which is generally more conserved and therefore routinely used for diagnostic purposes. Comparisons were made using this data, sequences from British isolates from the 1990s, as well as published information from other countries. All of the isolates analysed belonged to genotype 1 (Fig. 1), providing additional proof that genotype 2, introduced in Scandinavia and also found elsewhere in continental Europe (Balka et al., 2008), has not yet reached Britain. It therefore remains vital that the risk of importing genotype 2 virus from continental Europe or elsewhere is recognised and precautions are taken to reduce this risk.

Nucleotide sequence comparisons were generally consistent whichever of the three gene regions were examined. More variation than in ORF7 was seen in the other genes, where ORF5 is routinely used to screen for potential epidemiological links, and the broader diversity on the global scale is reflected in Fig. 1B compared to Fig. 1A. The most fundamental changes however were seen in ORF3 (Fig. 6) and ORF4 (data not shown) where the size of the gene product was sometimes affected by deletions or early terminations.

The detailed analysis of the resulting protein sequences for the nucleocapsid, GP5, GP5a and GP3 (Figs. 3-6) demonstrated that dispensible areas identified previously (Oleksiewicz et al., 2000) undergo higher mutation rates than those crucial for protein folding and function, such as cysteine residues forming disulphide bonds, as well as nglycosylation sites and signal sequences.

The observed increase in diversity of circulating PRRSV strains from the 1990s to the present is considerable, as the similarity of sequences dropped from $95 \%$ to $84 \%$ for some regions of the genome.

The data from ORF5 sequence analysis indicates that the population of British viruses so far characterised is descended from a common ancestral virus similar to the Lelystad and British $\mathrm{H} 2$ reference strains. This initial incursion is predicted to have occurred in 1991, which corresponds well with the available clinical and epidemiological data for the emergence of PRRS in Britain (Edwards et al., 1992). The similarity of early isolates from the Netherlands, Denmark, and Britain suggest a common origin for most of the cases in western Europe (Forsberg et al., 2001). The analysis of ORF7 sequences however suggests that beyond the initial introduction, three or four additional more recent incursions of PRRS virus into Britain may have occurred. This apparent discrepancy may be explained by the fact that different data sets are being used for both analyses, as matching ORF5 and ORF7 sequences from the same virus are rarely available, as well as by recombination events whereby the ORF5 or 7 sequences arise from different origins. The lack of sequence data from Britain and elsewhere between 1992 and 2004, and the limited amount of data available before and after that period preclude any certainty in the conclusions reached from the analyses, as it is quite possible that additional incursions of new virus strains have taken place, but have simply not yet been identified.
It is notable that virus strains similar to $\mathrm{H} 2$ and Lelystad continue to be isolated in Britain, showing relatively few changes in their genes encoding structural proteins. While these viruses contain too many nucleotide changes to represent re-isolation of virus from vaccinated animals, it is not inconceivable that they originate historically from vaccine, rather than representing continued circulation of particularly well-adapted field strains found in the 1990s. The branch length of the phylogenetic trees derived from this study supports the hypothesis that use of the modified live vaccine in Britain has exerted a selective pressure on the virus population, so that viruses quite different from the vaccine strain continue to evolve rapidly, while viruses similar to the vaccine are prevented from doing so as quickly. This is consistent with the idea that the use of this live vaccine is effective in restricting the circulation of some virus strains more effectively than others, indirectly pointing to a decreased efficiency towards challenge with a more diverse strain.

The discovery of field viruses very similar to the live vaccine virus was not entirely unexpected, since it has been previously reported elsewhere (Madsen et al., 1998; Nielsen et al., 2001, 2002; Kiss et al., 2006; Gross Beilage et al., 2009), but their isolation, in the absence of other field virus, from animals showing clinical signs of PRRS and their presence where vaccine has not been used is possibly cause for concern. Furthermore, the finding of a field virus which had undergone recombination with a vaccine or vaccine-like virus highlights an additional mechanism for the generation of ever-more diverse viruses. Such recombination events between field strains have previously been proposed for PRRSV (Yuan et al., 1999; Forsberg et al., 2002; Liu et al., 2011).

The demonstration of an increasing diversity among the population of PRRS viruses confirms earlier reports (Mateu et al., 2006; Fang et al., 2007; Li et al., 2009; Prieto et al., 2009; Shi et al., 2010) and indicates that challenges for diagnostic and immunisation methods increase accordingly (Labarque et al., 2004; Indik et al., 2005). The suggestion that using an attenuated vaccine may contribute to the emergence of new virus variants (Liu et al. 2011) highlights the need to better understand the dynamics of vaccine virus shedding, evolution, and recombination potential.

\section{Acknowledgements}

The authors wish to thank the UK Department for Environment Food and Rural Affairs for sponsoring this work (project SE0525). The authors are also grateful to the practitioners and farmers who submitted the samples and case histories which were used in this study. The provision of monoclonal antibody SDOW17 by Dr. D.A. Benfield (South Dakota State University) is also gratefully recognised.

\section{References}

An, T.Q., Zhou, Y.J., Qiu, H.J., Tong, G.Z., Wang, Y.F., Liu, J.X., Yang, J.Y., 2005. Identification of a novel $B$ cell epitope on the nucleocapsid protein of porcine reproductive and respiratory syndrome virus by phage display. Virus Genes 31, 81-87. 
Balka, G., Hornyak, A., Balint, A., Kiss, I., Kecskemeti, S., Bakonyi, T., Rusvai, M., 2008. Genetic diversity of porcine reproductive and respiratory syndrome virus strains circulating in Hungarian swine herds. Vet. Microbiol. 127, 128-135.

Drew, T.W., 1996. Studies on the Genome and Proteins of Porcine Reproductive and Respiratory Syndrome Virus. Open University Press, London, UK.

Drummond, A.J., Ho, S.Y.W., Phillips, M.J., Rambaut, A., 2006. Relaxed phylogenetics and dating with confidence. PLoS Biol. 4, e88.

Drummond, A.J., Rambaut, A., 2007. BEAST: Bayesian evolutionary analysis by sampling trees. BMC Evol. Biol. 7, 214-221.

Edwards, S., Robertson, L., Wilesmith, J., Ryan, J., Kilner, C., Paton, D., Drew, T.W., Brown, I., Sands, J., 1992. PRRS ("Blue-eared pig disease") in Great Britain. Am. Assoc. Swine Pract. Newsl. 4, 32-36.

Fang, Y., Schneider, P., Zhang, W.P., Faaberg, K.S., Nelson, E.A., Rowland, R.R., 2007. Diversity and evolution of a newly emerged North American Type 1 porcine arterivirus: analysis of isolates collected between 1999 and 2004. Arch. Virol. 152, 1009-1017.

Firth, A.E., Zevenhoven-Dobbe, J.C., Wills, N.M., Go, Y.Y., Balasuriya, U.B.R., Atkins, J.F., Snijder, E.J., Posthuma, C.C., 2011. Discovery of a small arterivirus gene that overlaps the GP5 coding sequence and is important for virus production. J. Gen. Virol. 92, 1097-1106.

Forsberg, R., Oleksiewicz, M.B., Petersen, A.M.K., Hein, J., Bøtner, A., Storgaard, T., 2001. A molecular clock dates the common ancestor of European-type porcine reproductive and respiratory syndrome virus at more than 10 years before the emergence of disease. Virology 289, 174-179.

Forsberg, R., Storgaard, T., Nielsen, H.S., Oleksiewicz, M.B., Cordioli, P., Sala, G., Hein, J., Bøtner, A., 2002. The genetic diversity of European type PRRSV is similar to that of the North American type but is geographically skewed within Europe. Virology 299, 38-47.

Gorbalenya, A.E., Enjuanes, L., Ziebuhr, J., Snijder, E.J., 2006. Nidovirales: evolving the largest RNA virus genome. Virus Res. 117, 17-37.

Gross Beilage, E., Nathues, H., Meemken, D., Harder, T.C., Doherr, M.G., Grotha, I., Greiser-Wilke, I., 2009. Frequency of PRRS live vaccine virus (European and North American genotype) in vaccinated and nonvaccinated pigs submitted for respiratory tract diagnostics in NorthWestern Germany. Prev. Vet. Med. 92, 31-37.

Guarino, H., Goyal, S.M., Murtaugh, M.P., Morrison, R.B., Kapur, V., 1999. Detection of porcine reproductive and respiratory syndrome virus by reverse transcription-polymerase chain reaction using different regions of the viral genome. J. Vet. Diagn. Invest. 11, 27-33.

Han, J., Wang, Y., Faaberg, K.S., 2006. Complete genome analysis of RFLP 184 isolates of porcine reproductive and respiratory syndrome virus. Virus Res. 122, 175-182.

Indik, S., Schmoll, F., Sipos, W., Klein, D., 2005. Genetic variability of PRRS virus in Austria: consequences for molecular diagnostics and viral quantification. Vet. Microbiol. 107, 171-179.

Jackson, G., Bidewell, C.A., Woodger, N.G.A., Williamson, S.M., Higgins, R.J., Frossard, J.P., Brown, I.H., Ryan, J.B.M., Robertson, S., Naidu, B., Banks, M., Drew, T.W., Cook, A.J.C., 2006. Viral pneumonia in pigs in England and Wales 1999-2005. Pig J. 58, 166-181.

Johnson, C.R., Griggs, T.F., Gnanandarajah, J., Murtaugh, M.P., 2011. Novel structural protein in porcine reproductive and respiratory syndrome virus encoded by an alternative ORF5 present in all arteriviruses. J. Gen. Virol. 92, 1107-1116.

Karniychuk, U.U., Geldhof, M., Vanhee, M., Van Doorsselaere, J., Saveleva, T.A., Nauwynck, H.J., 2010. Pathogenesis and antigenic characterization of a new East European subtype 3 porcine reproductive and respiratory syndrome virus isolate. BMC Vet. Res. 6, 30 (Art No. 30).

Keffaber, K.K., 1989. Reproductive failure of unknown etiology. Am. Assoc. Swine Pract. Newsl. 1, 1-10.

Kiss, I., Sami, L., Kecskemeti, S., Hanada, K., 2006. Genetic variation of the prevailing porcine respiratory and reproductive syndrome viruses occurring on a pig farm upon vaccination. Arch. Virol. 151, 22692276 .

Kumar, S., Tamura, K., Nei, M., 2004. MEGA3: integrated software for molecular evolutionary genetics analysis and sequence alignment. Brief Bioinform. 5, 150-163.

Labarque, G., Reeth, K.V., Nauwynck, H., Drexler, C., Van Gucht, S., Pensaert, M., 2004. Impact of genetic diversity of European-type porcine reproductive and respiratory syndrome virus strains on vaccine efficacy. Vaccine 22, 4183-4190.

Li, Y., Wang, X., Bo, K., Wang, X., Tang, B., Yang, B., Jiang, W., Jiang, P., 2007. Emergence of a highly pathogenic porcine reproductive and respiratory syndrome virus in the mid-eastern region of China. Vet. J. 174, 577-584.

Li, Y.F., Wang, X.L., Jiang, P., Wang, X.F., Chen, W., Wang, X.W., Wang, K.W., 2009. Genetic variation analysis of porcine reproductive and respiratory syndrome virus isolated in China from 2002 to 2007 based on ORF5. Vet. Microbiol. 138, 150-155.

Liu, D., Zhou, R., Zhang, J., Zhou, L., Jiang, Q., Guo, X., Ge, X., Yang, H., 2011. Recombination analyses between two strains of porcine reproductive and respiratory syndrome virus in vivo. Virus Res. 155, 473-486.

Madsen, K.G., Hansen, C.M., Madsen, E.S., Strandbygaard, B., Bøtner, A., Sorensen, K.J., 1998. Sequence analysis of porcine reproductive and respiratory syndrome virus of the American type collected from Danish swine herds. Arch. Virol. 143, 1683-1700.

Mateu, E., Diaz, I., Darwich, L., Casal, J., Martin, M., Pujols, J., 2006. Evolution of ORF5 of Spanish porcine reproductive and respiratory syndrome virus strains from 1991 to 2005. Virus Res. 115, 198-206.

Mathews, D.H., Sabina, J., Zuker, M., Turner, D.H., 1999. Expanded sequence dependence of thermodynamic parameters improves prediction of RNA secondary structure. J. Mol. Biol. 288, 911-940.

Meulenberg, J.J.M., Bende, R., Bos, J., Petersen-den Besten, A., de Kluyver, E., Wensvoort, G., Moorman, R., 1995. Molecular characterization of Lelystad virus. In: Abstracts of the Second International Symposium on Porcine Reproductive and Respiratory Syndrome (PRRS), Copenhagen, Denmark, August 9-10, 1995, p. 3.

Nelson, E.A., Christopher-Hennings, J., Drew, T.W., Wensvoort, G., Collins, J.E., Benfield, D.A., 1993. Differentiation of U.S. and European isolates of porcine reproductive and respiratory syndrome virus by monoclonal antibodies. J. Clin. Microbiol. 31, 3184-3189.

Nelson, E., Nelson, J.K., Couture, L.P., Lau, M.L., Christopher-Hennings, J., Chase, C.C.L., Hesse, R.A., 1997. A single amino acid substitution allows for the differentiation of the Prime Pac PRRS ${ }^{\mathbb{R}}$ vaccine from field isolates of PRRSV, abstr. 202. In: Proceedings of the 78th Conference of Research Workers in Animal Diseases, Chicago, IL.

Neumann, E.J., Kliebenstein, J.B., Johnson, C.D., Mabry, J.W., Bush, E.J., Seitzinger, A.H., Green, A.L., Zimmerman, J.J., 2005. Assessment of the economic impact of porcine reproductive and respiratory syndrome on swine production in the United States. J. Am. Vet. Med. Assoc. 227, 385-392.

Nielsen, H.S., Oleksiewicz, M.B., Forsberg, R., Stadejek, T., Bøtner, A. Storgaard, T., 2001. Reversion of a live porcine reproductive and respiratory syndrome virus vaccine investigated by parallel mutations. J. Gen. Virol. 82, 1263-1272.

Nielsen, J., Bøtner, A., Bille-Hansen, V., Oleksiewicz, M.B., Storgaard, T., 2002. Experimental inoculation of late term pregnant sows with a field isolate of porcine reproductive and respiratory syndrome vaccine-derived virus. Vet. Microbiol. 84, 1-13.

Normile, D., 2007. Virology. China, Vietnam grapple with 'rapidly evolving' pig virus. Science 317, 1017.

Oleksiewicz, M.B., Bøtner, A., Toft, P., Grubbe, T., Nielsen, J., Kamstrup, S., Storgaard, T., 2000. Emergence of porcine reproductive and respiratory syndrome virus deletion mutants: correlation with the porcine antibody response to a hypervariable site in the ORF3 structural glycoprotein. Virology 267, 135-140.

Oleksiewicz, M.B., Bøtner, A., Normann, P., 2002. Porcine B-cells recognize epitopes that are conserved between the structural proteins of American- and European-type porcine reproductive and respiratory syndrome virus. J. Gen. Virol. 83, 1407-1418

Prieto, C., Vázquez, A., Núńez, J.I., Alvarez, E., Simarro, I., Castro, J.M., 2009. Influence of time on the genetic heterogeneity of Spanish porcine reproductive and respiratory syndrome virus isolates. Vet. J. 180, 363-370.

Rossow, K.D., 1998. Porcine reproductive and respiratory syndrome. Vet. Pathol. 35, 1-20.

Shi, M., Lam, T.T.Y., Hon, C.C., Hui, R.K.H., Faaberg, K.S., Wennblom, T., Murtaugh, M.P., Stadejek, T., Leung, F.C.C., 2010. Molecular epidemiology of PRRSV: a phylogenetic perspective. Virus Res. 154, 7-17.

Snijder, E.J., Meulenberg, J.J.M., 1998. The molecular biology of arteriviruses. J. Gen. Virol. 79, 961-979.

Stadejek, T., Oleksiewicz, M.B., Scherbakov, A.V., Timina, A.M., Krabbe, J.S., Chabros, K., Potapchuk, D., 2008. Definition of subtypes in the European genotype of porcine reproductive and respiratory syndrome virus: nucleocapsid characteristics and geographical distribution in Europe. Arch. Virol. 153 (8), 1479-1488.

Stockhofe-Zurwieden, N., Weesendorp, E., Morgan, S., Rebel, A., 2011. Comparison of the pathogenesis of different european porcine reproductive and respiratory syndrome virus strains. In: Proceedings of the 6th International Symposium on Emerging and Re-emerging Pig Diseases, Centre de Recerca en Sanitat Animal (CReSA), Barcelona, June $12-15,2011$, p. 107

Thompson, J.D., Higgins, D.G., Gibson, T.J., 1994. CLUSTAL W: improving the sensitivity of progressive multiple sequence alignment through sequence weighting, position-specific gap penalties and weight matrix choice. Nucleic Acids Res. 22, 4673-4680. 
Tian, K., Yu, X., Zhao, T., Feng, Y., Cao, Z., Wang, C., Hu, Y., Chen, X., Hu, D., Tian, X., Liu, D., Zhang, S., Deng, X., Ding, Y., Yang, L., Zhang, Y., Xiao, H., Qiao, M., Wang, B., Hou, L., Wang, X., Yang, X., Kang, L., Sun, M., Jin, P. Wang, S., Kitamura, Y., Yan, J., Gao, G.F., 2007. Emergence of fatal PRRSV variants: unparalleled outbreaks of atypical PRRS in China and molecular dissection of the unique hallmark. PLoS One 2, e526.

Tong, G.Z., Zhou, Y.J., Hao, X.F., Tian, Z.J., An, T.Q., Qiu, H.J., 2007. Highly pathogenic porcine reproductive and respiratory syndrome, China. Emerg. Infect. Dis. 13, 1434-1436.

Wensvoort, G., de Kluyver, E.P., Luijtze, E.A., den Besten, A., Harris, L., Collins, J.E., Christianson, W.T., Chladek, D., 1992. Antigenic comparison of Lelystad virus and swine infertility and respiratory syndrome (SIRS) virus. J. Vet. Diagn. Invest. 4, 134-138.

Wensvoort, G., Terpstra, C., Pol, J.M.A., ter Laak, E.A., Bloemraad, M., de Kluyver, E.P., Kragten, C., van Buiten, L., den Besten, A., Wagenaar, F., Broekhuijsen, J.M., Moonen, P.L.J.M., Zetstra, T., de Boer, E.A., Tibben, H.J., de Jong, M.F., van't Veld, P., Groenland, G.J.R., van Gennep, J.A., Voets, M.T., Verheijden, J.H.M., Braamskamp, J., 1991. Mystery swine disease in the Netherlands: the isolation of Lelystad virus. Vet. Q. 13 (3), 121-130.

Wootton, S.K., Nelson, E.A., Yoo, D., 1998. Antigenic structure of the nucleocapsid protein of porcine reproductive and respiratory syndrome virus. Clin. Diagn. Lab. Immunol. 5 (6), 773-779.

Yoon, K.J., Zimmerman, J.J., McGinley, M.J., Landgraf, J., Frey, M.L., Hill, H.T., Platt, K.B., 1995. Failure to consider the antigenic diversity of porcine reproductive and respiratory syndrome (PRRS) virus isolates may lead to misdiagnosis. J. Vet. Diagn. Invest. 7, 386-387.

Yuan, S., Nelsen, C.J., Murtaugh, M.P., Schmitt, B.J., Faaberg, K.S., 1999. Recombination between North American strains of porcine reproductive and respiratory syndrome virus. Virus Res. 61, 87-98.

Zhou, Y.J., Hao, X.F., Tian, Z.J., Tong, G.Z., Yoo, D., An, T.Q., Zhou, T., Li, G.X., Qiu, H.J., Wei, T.C., Yuan, X.F., 2008. Highly virulent porcine reproductive and respiratory syndrome virus emerged in China. Transbound. Emerg. Dis. 55, 152-164.

Zuker, M., 2003. Mfold web server for nucleic acid folding and hybridization prediction. Nucleic Acids Res. 31, 3406-3415. 